\title{
PSICOLOGIA E BIOÉTICA: DIÁlOGOS
}

\author{
Hericka Zogbi Jorge Dias* \\ Gabriel José Chittó Gauer** \\ Rachel Rubin*** \\ Alessandro Valério Dias***
}

\section{RESUMO}

O presente artigo discute questôes acerca das intersecções entre a psicologia e a bioética. Muitos dos dilemas envolvendo a psicologia já são enfrentados por profissionais que atuam na saúde. Porém há aspectos teóricos importantes a serem considerados no estudo da psicologia hoje, como os dilemas morais comuns ao desenvolvimento humano em meio aos avanços tecnológicos tais como reprodução assistida, seleção de sexo, terminalidade, mas não somente estes. Consideraremos também como pertencentes ao campo da ética e da bioética as tarefas evolutivas do ser humano como a opção ou não pela maternidade/paternidade e as condições psíquicas e ambientais para esta decisão, entre outras. Dessa forma, propomos o diálogo entre bioética e psicologia no sentido de aproximar dois conhecimentos no intuito de repensar posturas e visões de mundo do profissional que atua diretamente com o humano.

Palavras-chave: psicologia, bioética, dilemas éticos

* Psicóloga; Doutoranda em Psicologia (Pontifícia Universidade Católica do Rio Grande do Sul); Bolsista CNPq; Membro da Diretoria da SORBI (Sociedade Rio-Grandense de Bioética).

** Psiquiatra; Professor Adjunto da Faculdade de Psicologia, Programa de Pós-Graduação em Psicologia, Programa de Pós-Graduação Gerontologia Biomédica da PUCRS; Colaborador do Programa de Mestrado em Ciências Criminais da PUCRS.

*** Graduanda em Psicologia PUCRS; Bolsista de Pesquisa PIBIC/CNPq, PUCRS.

**** Mestrando em Psicologia, PUCRS. 


\section{AbSTRACT}

\section{PsyChOlOGY AND BIOETHICS: DIALOGUES}

This article presents a discussion about questions surrounding the intersections between psychology and bioethics. Many dilemmas involving psychology are already being faced by professionals working with health. Although there are important theoretical aspects to be considered in the study of psychology today, such as the moral dilemmas common to human development in the middle of technological advances, like assisted reproduction, gender selection, terminality and others, but not only those. We also consider as pertaining to the fields of ethics and bioethics the evolutionary tasks of human beings, such as the option for maternity/paternity, and the mental and environmental conditions to these decisions, among others. That said, we suggest the dialogue between bioethics and psychology hoping to approach two areas of knowledge by aiming to reconsider the attitudes and the world views of professionals working directly with the humane.

Keywords: psychology, bioethics, ethical dilemmas

\section{INTRODUÇÃo}

$\mathrm{Na}$ atividade diária com os pacientes, os profissionais da área da saúde mental enfrentam situações que suscitam dúvidas sobre qual atitude tomar em seus atendimentos, não só do ponto de vista de condutas técnicas, mas, principalmente, no campo dos valores e da ética. Essas questões estão no contexto de reflexões da bioética, área do conhecimento que surgiu há, aproximadamente, 30 anos e que tem como objetivo estudar, sistematicamente, a conduta humana no que diz respeito às ciências da vida e da saúde.

A bioética preocupa-se em explicitar que toda a prática da saúde, antes de técnica, é invariavelmente um ato ético que necessita ser justificado e supõe uma responsabilidade moral (Gracia, 1998). A atividade do psicólogo como um ato de promoção de saúde, na atuação em psicoterapia, na intervenção grupal, comunitária ou organizacional, embora seja uma especialidade agrupada na área das ciências humanas, também faz parte do conjunto de procedimentos disponíveis para a promoção da saúde.

Nesse contexto, a psicologia desenvolve muitos dos conceitos propostos pela bioética. Tal como a medicina, a psicologia tende a fixar - erroneamente sua atenção mais no aspecto patológico da pessoa do que no aspecto saudável. Nesse sentido, a formação profissional aliada à formação pessoal do psicólogo é fator decisivo no estabelecimento de sua atuação profissional, considerando suas visões de homem e de mundo. 
A bioética possui caráter multi, inter e transdisciplinar: multidisciplinar por ser composta por profissionais de todas as áreas; interdisciplinar porque propõe o diálogo entre as disciplinas e transdisciplinar por transcender especialidades, criando um saber comum entre as áreas no benefício das pessoas e na resolução de dilemas éticos. Portanto, a bioética é uma ponte entre as ciências da saúde e os fundamentos éticos e filosóficos que devem reger o modo de agir de todos aqueles que estão comprometidos com a assistência à saúde.

\section{COMPREENDENDO QUESTÕES PSICOLÓGICAS NUM ENFOQUE BIOÉTICO}

A psicologia gradualmente vem se inserindo no campo da bioética, através da contribuição de seus diversos ramos. A psicologia social, por exemplo, preocupada e envolvida com todos os temas sociais, como a violência, a pobreza e o meio ambiente, oferece grandes contribuições a estas que são grandes preocupações do homem hoje e aos temas mais abrangentes da bioética. Da mesma forma, a psicologia clínica, talvez com uma aplicação mais evidente, contribui com um pensamento sobre questóes da relação do psicólogo, como profissional de saúde, com seus pacientes.

A todo o momento o ser humano passa por situações em que pode avaliar moral e eticamente suas atitudes e escolhas. Sendo a bioética uma ética da vida, tudo aquilo que diz respeito à pessoa e ao outro está nela contida. Daí pode-se ir até as questôes do avanço da tecnologia nas ciências biomédicas, que, originalmente, deu força à bioética. Contudo, não se pode descuidar de questôes mais rotineiras, comumente chamadas de decisões de vida, para as quais os psicólogos são muitas vezes procurados a fim de fornecer auxílio.

Há quem pense que os princípios éticos, bem como as questões das quais a bioética se ocupa, são aplicáveis apenas às áreas biomédicas, não podendo ser transportadas para a psicologia, por exemplo. No entanto, assim como a medicina, a psicologia, na maioria das vezes, trata das pessoas no momento em que se encontram mais fragilizadas. Assim, os dilemas éticos encontrados na área da saúde, em função, principalmente, dos avanços da tecnologia, não são menos facilmente encontrados nessa área (Ludwig, Zogbi, Redivo \& Muller, 2005).

Podemos comparar o desenvolvimento tecnológico das ciências biomédicas com as mudanças de paradigma sofridos pela psicologia ao longo do tempo (Oliveira, Muller \& Zogbi, 2006). Ambos os acontecimentos traduzem-se em dilemas éticos, pois mobilizam profissionais e pacientes na reequilibração de conceitos pré-existentes sobre o que é certo e errado e sobre o que tais mudanças podem modificar na vida das pessoas. 
Para compreender questões de vida e mudanças paradigmáticas, na psicologia foram surgindo diferentes teorias psicológicas, com linguagens e métodos diferenciados de trabalho. Desde seu surgimento, a psicologia passa por uma série de transformaçóes e releituras, daí o aparecimento de diversas linhas de pensamento psicológico para o entendimento do ser humano. Num primeiro olhar, são divergentes, num segundo, todas têm o mesmo objetivo: compreender processos humanos. Se o fazem por caminhos diferentes, chegam a um ponto comum.

A vertente teórica existencial e fenomenológica, por exemplo, que dá bases a algumas linhas psicológicas que conhecemos (Gestalt-terapia, Psicodrama, Logoterapia e outras), com expoentes que podemos situar como Sartre (1984) e Buber (2003), frisam a importância da relação no desenvolvimento da pessoa. É preciso uma confirmação do outro para que se possa criar uma identidade, um ego organizado. Mesmo as situações de psicopatologia pressupõem um tipo de organização e se traduzem em dilemas éticos, no momento em que a pessoa em tratamento se encontra com determinadas características consideradas patológicas, por exemplo. A visão de mundo do profissional psicólogo (um outro) e sua concepção ética e bioética da pessoa é que diferencia doença ou sofrimento. Dependendo do ponto de vista, a intervenção será focada na mera remissão do sintoma, ou no tratamento integral da pessoa.

Questôes bioéticas na psicologia têm recebido gradual interesse de pesquisadores. Contudo, embora tenha havido um aumento no número de artigos científicos que tratam da bioética e da psicologia, este número ainda é escasso perante o volume de publicaçôes em outras temáticas. Em consulta a bases de dados em janeiro de 2007 (Proquest, Proquest Dissertations, ISI Web of Knowledge, Medline, Applied Social Sciences Index and Abstracts, Cross-reference search, Scopus, Wilson Web e SciElo), foram identificados 77 artigos com texto completo, publicados entre os anos de 1995 e 2007, cujas palavras-chave eram "psychology" and "bioethics". Observou-se que, anterior a esse período, há uma escassez significativa de artigos com estas palavras-chave, indicando que o interesse na interface bioética-psicologia é bastante recente. As questôes mais atuais debatidas em artigos publicados recentemente vão desde as novas tecnologias reprodutivas na reprodução humana assistida aos aspectos psicossociais envolvidos (Castro, 2006), questôes bioéticas que permeiam a conduta do profissional de saúde (Kebbe, Ferreira, Rossi, 2004); bioética, envelhecimento e interdisciplinaridade (Soares, Pereira, Sobral, Fernandes, Portela, Hissa, Hissa, Fabiano \& Piñeiro, 2004); cuidado paliativo e trabalho hospitalar (Simoni \& Santos, 2003); bioética e a psicologia da saúde envolvendo reflexôes sobre questôes de vida e morte (Torres, 2003); bem como a relação médico-paciente (Nascimento \& Guimarães, 2003). 


\section{DiLEMAS BIOÉTICOS EM PSICOLOGIA}

Muitas das questôes diárias, até mesmo corriqueiras, que fazem parte da vida das pessoas, se vistas com atenção, podem caracterizar-se em dilemas bioéticos com substrato psicológico. Isto desde o nascimento, considerando as questôes psicológicas envolvidas na escolha do cônjuge e na opção - ou não - pela maternidade/paternidade, até questôes mais complexas, como o aborto, a eutanásia e a questão da terminalidade e da morte, passando, assim, por todo o desenvolvimento do ser humano.

Essa realidade pode ser transposta para o processo psicoterápico no momento em que o paciente tenta colocar para o terapeuta tudo o que há de mais íntimo para seu melhor tratamento. Isso reflete a importância do respeito às questões do sigilo e da privacidade aplicados às psicoterapias. Assim, é importante que se faça uma reflexão sobre os dilemas éticos que atravessam a psicoterapia que, muitas vezes, não estão na superfície das preocupações, mas, sim, a partir de um olhar direcionado às questões do ser humano.

Os psicólogos têm conquistado importantes espaços dentro dos hospitais e outras instituições de saúde e também de pesquisa em saúde. Com freqüência o psicólogo é solicitado a auxiliar em situações difíceis para as equipes que atendem os pacientes, que vão desde um caso de resistência em aceitar tratamento médico, situações nas quais sintomas moderados de ansiedade e depressão podem estar presentes, até problemas que tornam mais complexa a problemática da reflexão ética sobre determinada situação.

A atuação do psicólogo no âmbito da saúde traz alguns importantes dilemas, como os que serão abordados a seguir. Um desses dilemas diz respeito ao início da vida. Mesmo o curso normal ou esperado de uma gestação traz dilemas como o desejo, os aspectos emocionais entre os pais, a situação ambiental e social da família. Com o avanço da tecnologia, outros dilemas surgem, e a possibilidade de seleção do sexo dos bebês traz indagações bastante profundas: qual a intenção dos pais na escolha do sexo do seu bebê? Qual a finalidade de tal escolha no contexto familiar e de casal e no contexto social? Em algumas sociedades como China e Índia, essa prática tem sido comum ao longo da história, nem sempre de forma refletida, mas em geral por meio de aborto, infanticídio e negligência, em busca de um filho homem (Muller, Matta \& Zogbi, 2004). Para as mesmas autoras, em se tratando de questões de gênero, é preciso investigar entre os pais que querem optar pela seleção de sexo quais as suas motivações, inclusive as inconscientes.

Para a psicologia do desenvolvimento e da família, é sabido que para um casal que está, acima de tudo, comprometido com o bem-estar da criança pouco 
importará o sexo do filho. Por essa razão, é essencial que se reflita a respeito das escolhas de parceiros e do "contrato secreto" que se dá entre casais. Corrêa (2001) traz o pertinente comentário sobre o quão difícil é determinar em que medida a reprodução humana é um exercício da vontade individual e em que medida é produto de condicionamentos sociais.

$\mathrm{O}$ aconselhamento genético envolvendo pessoas portadoras de transtornos mentais também tem sido umas das questôes que dizem respeito diretamente à psicologia e à bioética. Trippiteli, Jamison, Folstein, Bartko e Depaulo (1998) conduziram uma pesquisa com casais em que um dos cônjuges possuía transtorno afetivo bipolar. Os resultados indicaram que os casais fariam testes genéticos para identificar bipolaridade nos filhos, mas, se fossem identificados genes relacionados com a bipolaridade, não abortariam os fetos.

Partindo em direção às questões referentes ao fim de vida, a terminalidade hoje é um fenômeno controverso, desde as possibilidades tecnológicas de fertilização até as de extensão da vida, sem necessariamente contar com os aspectos de qualidade das vidas em questão. Este problema envolve a própria definição de vida, sobrevida e qualidade de vida. Pessoas em situação de uma doença terminal têm características e necessidades emocionais e físicas bastante diferentes de pessoas saudáveis ou com doenças não terminais, o que exige novamente a reconstrução de saberes do psicólogo que atua com estas populações.

É dever do profissional de saúde concordar em estender indefinidamente a vida, mesmo que esteja irreversivelmente relacionada a aparelhos ou outros? Quando pode ser incluído no tratamento o desejo do paciente ou da família de continuar vivendo ligado a aparelhos? Que impacto têm essas decisões sobre a equipe de atenção ao paciente e à família? A doença é a experiência de fragilidade que provoca na situação terminal a consciência aguda da mortalidade, da finitude da existência. No momento da terminalidade, estamos diante da experiência-limite da existência. Essa experiência pode trazer um misto de angústia, mistério e profunda intimidade consigo mesmo (Müller; Matta \& Zogbi, 2004).

Além da atenção diferenciada na questão da terminalidade, alguns tópicos são importantes no que tange à atuação do psicólogo, como o direito ao diálogo e o direito à verdade. Quanto ao diálogo, este pode vir a ser penoso, porém é necessário e deve ser mantido. Negar esta possibilidade é desconhecer o fundamento existencial de uma experiência essencialmente humana. $\mathrm{O}$ direito à verdade caracteriza como dilema ético o fato de comunicar ou não ao paciente o seu estado de saúde ou seu diagnóstico, seja no âmbito da saúde física ou mental. Privar o paciente do direito ao diálogo envolve privá-lo das informações a respeito do tratamento, dos efeitos colaterais e também dos benefícios. Ao mesmo tempo, o diag- 
nóstico pode ter um peso tão importante sobre sua vida que o faça fechar os olhos para tais aspectos. Segundo os princípios bioéticos, privá-lo da verdade não seria retirar-lhe a autonomia? O dilema está muito mais na forma e no momento adequados para a revelação ou não do diagnóstico do que em fazê-lo.

Existem ainda outras situações que tocam, por exemplo, na quebra da confidencialidade. São aquelas relacionadas ao abuso de crianças e ao risco de vida para o próprio paciente ou para os outros, como nos casos de tentativa de suicídio ou homicídio. Aqui se torna fundamental que o psicólogo tenha conhecimento dos aspectos éticos envolvidos e das limitações colocadas pelo seu código de deveres. As questões bioéticas vão muito além do estabelecido em códigos deontológicos; partem de princípios que podem e devem ser flexibilizados para a resolução dos dilemas.

No âmbito da psiquiatria, de acordo com Loch, Gauer e Kipper (2003), a relação médico-paciente possui características especiais devido à vulnerabilidade dos pacientes que são atendidos. Os autores dizem que o psiquiatra (assim como o psicólogo) pode infringir os direitos humanos mais elementares e manipular a consciência dos pacientes com facilidade, já que possui acesso ao mais íntimo do ser humano.

Uma importante autora espanhola da bioética, Maria Casado (1996), levanta duas questôes que considera importantes no âmbito da psicologia e da psiquiatria: o tratamento com eletrochoque e o recurso de técnicas psicocirúrgicas. Salienta que tais intervenções exigem o consentimento do paciente, uma vez informado da sua natureza e dos efeitos da terapia a que vai se submeter. Porém alguns pacientes psiquiátricos não têm condições de oferecer esse consentimento devido ao seu estado. Assim, é necessário e exigido o consentimento da família do enfermo para realizar o tratamento. Nesses casos, sabemos das implicações muitas vezes dirigidas às famílias de pacientes altamente comprometidos, não sendo elas também, na maior parte das vezes, as melhores fontes de acesso para resoluções dilemáticas.

\section{UM PRINCÍPIO IMPORTANTE PARA O PSICÓlOGO: A AUTONOMIA}

A questão da autonomia é um ponto importante na discussão entre psicologia e bioética. Ela se refere à capacidade que a pessoa possui para decidir sobre aquilo que julga ser o melhor para si mesma. Para considerar uma pessoa autônoma, são necessárias algumas condições principais. Primeiramente, ela deve possuir a capacidade para compreender, analisar logicamente uma situação (racionalização) e habilidade para escolher entre várias hipóteses (deliberação) com o objetivo 
de decidir-se intencionalmente por uma das alternativas que lhe são apresentadas. Em segundo lugar, esta escolha só poderá ser considerada autônoma, própria, se a pessoa estiver livre de qualquer influência para tomar esta decisão (voluntariedade). A possibilidade de escolha autônoma de uma pessoa a respeito de sua vida, e as implicaçôes que essas decisões terão na vida dos demais e, por assim dizer, na construção da sociedade como um todo são uma discussão que pertence ao âmbito da bioética e da psicologia.

$\mathrm{O}$ princípio de respeito à autonomia baseia-se na dignidade da pessoa humana e, em conseqüência, há um dever moral de tratar a pessoa como um fim em si mesma e nunca utilizá-la como um meio para atingir determinado objetivo. É o reconhecimento do direito da pessoa de ter opiniōes e de agir segundo seus valores e convicções, de possuir um projeto de vida e felicidade baseado em escolhas próprias (Loch, Gauer \& Kipper, 2003).

No relacionamento da equipe de saúde com o paciente, o respeito ao princípio de autonomia favorece o diálogo, o entendimento e a confiança mútua que permitem ao paciente dar seu consentimento para a realização de intervençôes sobre seu corpo propostas pelo profissional com a intenção de melhorá-lo ou curá-lo. É obrigação do profissional fornecer ao paciente ou à família a mais completa informação possível a fim de promover uma compreensão adequada do problema, discutindo com ele as opçōes diagnósticas e terapêuticas cabíveis, ajudando-o a escolher aquela que lhe é mais benéfica. Este processo é conhecido como consentimento informado, consentimento livre e esclarecido ou consentimento pós-informação. Pode ser definido como uma decisão voluntária, verbal ou escrita, protagonizada por uma pessoa autônoma e capaz, tomada após um processo informativo, para a aceitação de um tratamento específico ou experimentação, consciente de seus riscos, benefícios e possíveis conseqüências (Gauer, Borges, Vasconcellos, Ávila, Ávila, Ferreira \& Ronchetti, 2006).

Existem outras circunstâncias especiais que limitam ou impedem a obtenção do consentimento informado: 1) as situaçôes de urgência, quando se necessita intervir e não se pode obtê-lo porque o doente está inconsciente ou em risco de vida; 2) a obrigação legal de notificação de algumas doenças infecciosas às autoridades sanitárias; 3) os casos em que a patologia ou as informações reveladas pelo paciente possam afetar gravemente a saúde ou a vida de outras pessoas, cuja identidade é conhecida - situação que obriga o médico a revelar dados confidenciais mesmo que o paciente não autorize; 4) e quando o próprio paciente se recusa a receber esclarecimentos ou participar das decisóes sobre seu tratamento (Gauer, Borges, Vasconcellos, Ávila, Ávila, Ferreira \& Ronchetti, 2006). Essas são im- 
portantes questôes que freqüentemente surgem nas discussóes na academia e na formação de jovens psicólogos.

Toda intervenção psicológica deve pretender a autonomização do paciente, não a sua manipulação e a promoção da dependência. A relação clínica não será satisfatória e estará sendo violada sempre que o psicólogo se utilizar de seus conhecimentos para alcançar outros objetivos que não o bem-estar e o respeito aos legítimos interesses e direitos dos pacientes (Gauer, Borges, Vasconcellos, Ávila, Ávila, Ferreira \& Ronchetti, 2006).

\section{CONSIDERAÇÕES FINAIS}

A vida modifica-se continuamente, é movimento, está inscrita no tempo de forma irreversível e é acompanhada em simultâneo pela inovação, vista aqui como a força proveniente dessa dinâmica. A capacidade de inovar e criar, influenciando o curso dos fatos, nem sempre segue as premissas éticas. Embora a intencionalidade, como capacidade de escolha do homem, que surge em um dado ponto de sua trajetória, nem sempre seja precedida de uma profunda reflexão ética. Esses aspectos, por si sós, justificam a necessidade de se ligar o cotidiano das instituições de saúde que desenvolvem o atendimento com base em técnicas adquiridas através dos novos conhecimentos na área assim como o acompanhamento de situações nas quais esses conhecimentos provocam tensōes e conflitos.

Os avanços da ciência tornam a relação do profissional de saúde mental com seus pacientes mais complexa do que em outros tempos. A busca pelo respeito à dignidade e integridade do outro são aspectos básicos no fazer de todo psicólogo. Podemos traduzir a atuação do psicólogo como autonomia, beneficência e justiça, pilares básicos do viver humano (Muller, 2001).

É absolutamente necessário que se inclua na formação do profissional de saúde mental, do mesmo modo que se treinam os estudantes nas discussões dos aspectos técnicos, uma capacitação para resolver os conflitos éticos que surgem da prática assistencial, desenvolvendo seus aspectos afetivos e humanos e visando sua competência para estabelecer uma adequada relação médico-paciente (Gauer, Borges, Vasconcellos, Ávila, Ávila, Ferreira \& Ronchetti, 2006).

Sabendo que o principal ponto de discussão entre bioética e psicologia é o respeito ao ser humano, não se pode deixar de lado o fato de que qualquer intervenção, mesmo sendo no campo psíquico, mobilizará conteúdos com os quais o paciente pode ainda não estar disposto a entrar em contato. Assim como a bioética reflete cada dilema com suas peculiaridades, acredita-se que na ação do psicólogo se deva proceder da mesma forma. É necessário que essa mentali- 
dade evolua, sendo a psicologia um campo de estudos que não pode ser afastado das discussões bioéticas.

\section{REFERÊNCIAS BIBLIOGRÁFICAS}

Buber, M. (2003). Eu e tu. São Paulo: Centauro.

Casado, M. (1996). Material de bioética y derecho. Barcelona: Cedecs Editorial.

Castro, C. M. (2006). Questôes psicossociais em novas tecnologias reprodutivas: estudo qualitativo em um serviço público de reprodução humana assistida. Tese de Doutorado, Secretaria da Saúde, Coordenadoria de Controle de Doenças, Programa de Pós-Graduação em Ciências, São Paulo.

Corrêa, M. (2001). Ética e reprodução assistida: a medicalização do desejo de filhos. Bioética, 9 (2), 71-82.

Gauer, G. C.; Borges, G. S.; Vasconcellos, S. J. L.; Ávila, G. N. de; Ávila, G. A. de; Ferreira, V. R. T. \& Ronchetti, R. (2006). Determinando a competência dos pacientes em tomadas de decisóes quanto aos seus tratamentos. Revista Eletrônica da SORBI, v. 1, no 3 .

Gracia, D. (1998). Bioética clinica. Bogotá: El Búho.

Kebbe, L. M.; Ferreira, C. B. \& Rossi, L. (2004). Profissionais de saúde na assistência a pacientes fora de possibilidades terapêuticas. Psicologia Argumento, 22 (38), 55-63.

Lock, J. A; Gauer, G. J. C. \& Kipper, D. J. (2003). Bioética, psiquiatria e estudante de medicina. Em Cataldo Neto, A.; Gauer, G. J. C. \& Furtado, N. R. (Orgs.). Psiquiatria para estudantes de medicina (pp. 91-97). Porto Alegre: EDIPUCRS.

Ludwig, M. W. B.; Zogbi, H. J; Redivo, L. B. \& Muller, M. C. (2005). Dilemas éticos em psicologia: psicoterapia e pesquisa. Revista Eletrônica da Sociedade Rio-Grandense de Bioética, 1 (1). Disponível em (http://www.sorbi.org.br/revista/1/ bioetica_e_psico_SORBI.pdf). Acesso em: 18/07/2007.

Muller, M. C. (2001). Psicologia e bioética. Em Clotet, J (Org.). Bioética (pp. 85-92). Porto Alegre: EDIPUCRS.

Muller, M. C.; Matta, A. Z.; Zogbi, H. J. (2004). O princípio da autonomia em seleção de sexo: aspectos psicológicos. Em Clotet, J. \& Goldim, J. R. (Orgs.). Seleção de sexo e Bioética (pp. 57-68). Porto Alegre: EDIPUCRS.

Nascimento Júnior, P. G. \& Guimarães, T. M. M. (2003). A relação médico-paciente e seus aspectos psicodinâmicos. Bioética, 11 (1), 101-114.

Oliveira, M.; Muller, M. C. \& Zogbi, H. J. (2006). Dilemas éticos na pesquisa em psicologia. Em Kipper, D. J. (Org.) Ética: teoria e prática - uma visão multidisciplinar (pp. 186-199). Porto Alegre: EDIPUCRS. 
Sartre, J.-P. (1984). O existencialismo é um humanismo. São Paulo: Abril Cultural.

Simoni, M. \& Santos, M. L. (2003). Considerações sobre cuidado paliativo e trabalho hospitalar: uma abordagem plural sobre o processo de trabalho de enfermagem. Psicologia USP, (14) 2, 169-194.

Soares, A. M. M.; Pereira, A. T.; Sobral, B.; Fernandes, H. P. X.; Portela, J.; Hissa, M. G.; Hissa, M. T. D.; Fabiano, P. C. C. \& Piñeiro, W. E. (2004). Bioética, envelhecimento e interdisciplinaridade. Rio de Janeiro: Papel Virtual.

Torres, W. C. (2003). A bioética e a psicologia da saúde: reflexões sobre questôes de vida e morte. Psicologia: Reflexão e Crítica, (16) 3, 475-482.

Trippitelli, C. L.; Jamison, K. R.; Folstein, M. F.; Bartko, J. J. \& Depaulo, J. R. (1998). Pilot study on patients' and spouses' attitudes toward potential genetic testing for bipolar disorder. American Journal of Psychiatry, (155) 7, 899-904.

Recebido em 25 de abril de 2007 Aceito para publicação em 24 de julho de 2007 